\title{
TRANSCRIPCIÓN DE DOCUMENTOS RELATIVOS A LA PRIMERA FORTALEZA DE SANTA CRUZ DE TENERIFE*
}

\author{
Alberto García Montes de Oca**
}

\section{RESUMEN}

La transcripción de los documentos que presentamos permitirá recomponer de una manera más fehaciente la traza urbana del Santa Cruz del segundo tercio del siglo Xvi. En especial, las transcripciones se centran en la motivación, traza y desarrollo de la fortaleza de Santa Cruz entre 1552 y 1568 . Se trata de un estudio sobre el urbanismo defensivo del lugar y la época, que completa las interpretaciones someras y confusas que se han dado hasta la actualidad. Ofrecemos fuentes primarias y directas de un estudio imbricado en el proyecto Carta Arqueológica Subacuática de Tenerife, donde se muestra de manera explícita la necesidad de defender el fondeadero y muelle del lugar ubicado en el entorno norte, este y sur más próximo al baluarte y fortaleza. De la misma manera, se esclarecen preceptos documentales sobre la ubicación de la ermita de Nuestra Señora de la Consolación en esas fechas.

Palabras Clave: Santa Cruz, fortaleza, siglo xvi, puerto, defensas.

\section{TRANSCRIPTION OF THE DOCUMENTS RELATED WITH THE FIRST FORTRESS OF SANTA CRUZ DE TENERIFE}

\section{Abstract}

The transcription of the documents presented below will allow to fix, in a more solid manner, the urban trace of Santa Cruz as it was in the second third of the Xvi ${ }^{\text {th }}$ Century. The transcriptions focus especially on the incentives, traces and development of the Santa Cruz Fort between 1552 and 1568. It is a detailed study about the defensive planning of the location during this time, that complete the drafts and interpretations that have been written up until now surrounding this issue. I offer primary and direct sources, in association with the larger project named Subaquatic Archaeological Chard of Tenerife. The data presented here shows clearly the need of defending the anchorage and the dock of the place of Santa Cruz, located in the Northern, Eastern and Southern area of the bastion and fort. Moreover, this would help clarify the documentary precepts about the location of the Hermitage of Nuestra Señora de la Consolación in this period.

Keywords: Santa Cruz, fortress, $\mathrm{XvI}^{\text {th }}$ Century, harbour, defenses. 
Cuando un investigador se enfrenta a una realidad histórica, o, al menos, a su interpretación más plausible, ha de hacerlo siempre comparando, contrastando y confrontando fuentes documentales de cualquier tipo. Las fuentes directas y primarias son las más sólidas, puesto que fueron contemporáneas al registro de los hechos que contienen y no han sufrido interpretaciones por otras personas. Los documentos oficiales, como los que aquí se exponen, son los documentos escritos con la información más objetiva posible, teniendo, en este caso, que dar cuentas sólo al rey y sus secretarías de lo que en ellos se recoge, siendo la institución emisora la de más alto rango en la Isla de Tenerife.

De esta manera, para que el estudio adquiera rigor científico, se facilitará un enlace, para que digitalmente otros investigadores puedan corroborar o rebatir las transcripciones, sin que haya, por tanto, un punto de vista y una interpretación unilaterales. Ofrecer al público la fuente primaria, partiendo de la digitalización de esas páginas, a la vez que se ofrece su interpretación, pone en marcha el aparato crítico, que, aun así, se ve modificado por la selección de páginas específicas de entre un conjunto documental enorme. Con ello, científicos y público pueden corroborar la veracidad de las fuentes y la interpretación hecha, ya que en muchas ocasiones se nos ha ofrecido una interpretación de la historia un tanto sesgada o incompleta. He decidido que el lector no versado que quiera aprender a leer paleografía castellana procesal del siglo xvi pueda así también hacerlo, con los textos corroborables con las imágenes. De igual forma, considero que es el método más transparente para acercar las fuentes primarias a investigadores y público en general, que, debido a la existencia barreras geográficas, pueda acudir así a su formato digital ${ }^{1}$.

La siguiente selección de textos hace referencia a la construcción de la primera fortaleza de Santa Cruz de Tenerife, la motivación que impulsó su edificación y su progreso evolutivo en el segundo tercio del siglo xvi, antes de la construcción del Castillo de San Cristóbal. Estas transcripciones acompañan al estudio documental hecho por mí y por José Miguel Rodríguez Illescas sobre la evolución del lugar de Santa Cruz de Tenerife y Puerto Real en el segundo tercio de dicha centuria.

De esta manera, en la transcripción de los textos y su adecuación definitiva al formato de este artículo, he optado por mantener la grafía original del texto, añadiendo signos de puntuación para hacer inteligible el desarrollo textual, y añadiendo tildes, que tal vez pudieran ser consideradas diacríticas, ya que, aunque en la grafía original no las hubiere, están por el simple hecho de hacer más inteligibles

* Dedicado a mi madre, quien siempre me apoyó en mi trabajo e ilusiones. De igual manera, agradezco la revisión del abstract a Ángel Rafael González Orozco, y la primera lectura de las transcripciones a Miguel Díaz Díaz y a José Miguel Rodríguez Illescas, todos buenos amigos y colegas de la rama de Humanidades.

** Historiador, arqueólogo especialista en prospección arqueológica subacuática. Director del proyecto Carta Arqueológica Subacuática de Tenerife, vicepresidente de SONARS-Asociación Nacional de Arqueología Subacuática, director de la sección de Patrimonio Cultural Sumergido de FEDECAS. Email: albertogmdo@gmail.com.

${ }_{1}$ Las imágenes serán colgadas en la página https://www.facebook.com/sonars.arqueologia/. 
los textos. Así, las firmas y palabras al margen escritas en dos renglones muestran con una barra oblicua la división del renglón. Se añaden igualmente palabras que aclaran la lectura entre paréntesis.

Los textos a exponer son cuatro, todos ellos de las letras ' $F$ ' y ' $R$ ' de la sección primera del Fondo Antiguo del Archivo Municipal de La Laguna:

El primero, extraído de la carpeta número 2 de la letra 'F IX' (Fortificaciones), relata los motivos por los que se implementó la construcción del baluarte, plaza y fortaleza de Santa Cruz, y las características que debía tener. El rango de fechas va desde 1552 a 1554.

El segundo, extraído de la carpeta número 3 de la misma signatura, indica, ya avanzada la construcción de la fortaleza, sus características físicas y recomendaciones que para ella se hacen. En esta carpeta, hay un documento posterior, que se citará en cuarto lugar. El rango de fechas va desde 1557 a $1568^{2}$.

El tercero, extraído de la carpeta número 7 de la letra 'R VI' (Reales Cédulas), engloba algunas de las diligencias encargadas al criado de la princesa, hermana de Felipe II, don Alonso Pacheco, comisionado para, entre otras cosas, estudiar la evolución en la construcción de las fortalezas de Canarias y enviar informe a la Corona.

El cuarto, el último documento de la carpeta número 3 de la signatura ' $F$ IX', es un documento que engloba las propuestas que el alcaide de la fortaleza en ese momento, Juan Sánchez de Zambrana, propone para mejorar las características de la fortaleza y extender el terraplén hacia el este, sobre la laja de basalto sobre la que se encuentra, para dar cobertura de fuego a los abrigos que se hallaban inmediatamente al norte de la caleta que posteriormente sería conocida como la caleta de la Aduana. Este escrito va acompañado de un dibujo a mano alzada, un boceto sobre la propuesta que quiere implementar, así como diversos dibujos que, por la extrapolación de mi comportamiento a la hora de estudiar este documento, son garabatos de propuestas de plantas, alzados y perfiles de dicho edificio.

Antes de exponer las transcripciones, queda por aclarar que los nombres dados a las carpetas del catálogo del Archivo Municipal de La Laguna, al menos para estos casos, es meramente orientativo, puesto que incorporan un sinfín de datos más. Todas las acepciones explicadas en las notas a pie de página provienen de la versión web de la Real Academia Española, a excepción de una, que viene seńalada.

ReCiBIDO: 11-5-2020; ACEPTADO: 11-6-2020

${ }^{2}$ Hay interpretaciones que atribuyen el documento de 1568 a 1557, por encontrarse en la carpeta que engloba la descripción de la fortaleza de 1557, atribuyendo erróneamente un boceto de dicho documento al encargado de la obra, Francisco Merino. 


\section{TEXTOS}

\section{Sobre la necesidad de construir una fortaleza en Santa Cruz}

1 Recto +

Ynventario de la artilleria e muniçion del lugar e puerto

de Santa Cruz, que se entrego a Diego Perez Lorenço, Mayordomo e Guarda

Mayor de la dicha artillería, por prinçipio de julio de 1552 años.

Uno

IUdLII $^{3}$ años

Aquí esta como se mando hazer una fortaleza

en el puerto de Santa Cruz para defensa de la isla.

$[\ldots]$

5 Vuelto

Yten, se le manda que la dicha artilleria tenga puesta en las partes que al presente esta.

E si le pareçiere al dicho Diego Perez que conviene de sacar la que mas esta en el almazen,

o mudar de una parte a otra toda la dicha artilleria o parte della, se le da

facultad que lo pueda hacer, con tanto que no las saque fuera de los baluartes

o del desenbarcadero del pueblo.

[...]

Otrosi, que (a) tales del lugar de Santa Cruz, no consienta ny dé lugar que por las troneras

de cara las Carniçerias, ny dentro de la plaça de la artillería, nynguna persona eche basura.

E si la echaren, las prenda e les haga todo a linpiar a su costa. Lo qual todo se guarde e cunpla hasta que otra cosa se provea.

[...]

9 Recto

En el lugar e puerto de Santa Cruz, treynta dias del mes

de julio, año del Señor de myll e quinientos e çinquenta e tres años. El

muy magnifico señor liçenciado Fernando Myranda, gobernador e justiçia mayor desta dicha

isla, e los señores Juan Baptista de Arguijo e dotor Juan de

Fiesco, rregidores de la dicha isla, en presençia de my, Juan Lopez de Açoca, escrivano mayor del qabildo de la dicha ysla:

Luego, los señores Gobernador e rregidores dixeron: que por quanto oy se probeyo en la çibdad, por todos los señores del rregimiento que se juntaron, que se probeyese una barca luego a La Palma, y (que) se escriviese a

la Justiçia e rregimiento de la dicha ysla, para que hiziesen saber 
lo alli subçedido, e si era nesçesario que desta ysla fuesen de alguna cosa probeydos. Evienen en cumplimyento dello e de lo demas probeido sobre ello, e para poner por obra lo dicho, ${ }^{4}$ mandaron llamar $\mathrm{a}^{5}$ Baltasar Mateos, vecino deste lugar, para que fuese con su barca al dicho lugar e puerto de La Palma, o a la Punta Llana, o a la parte que mas le pareçiese que convenga, e lleve en ella a Juan Guillen, que va por mensajero ${ }^{6}$

[...]

9 Vuelto

E luego, nonbraron por guardas e çentinelas, para que sean en las bandas de Anaga, en la parte e lugar que primero esta señalado, a Juan Melian e Juan de Parraga

[...]

E luego, acordaron e mandaron que quatro moradillas de casas que tiene Gonzalo Martyn, junto al baluarte, en este lugar, se conpren, porque ynpiden y estorban la juntía del artilleria las dichas casas?

Rúbricas: Hernando/ Myranda, Juan Batista/ de Arguijo, Dotor/ Fiesco 10 Recto +

En el lugar e puerto de Santa Cruz, que es en la ysla de Thenerife, en dos dias del mes de agosto, año del Señor de myll e quinientos e çinquenta e tres años. Se juntaron en el dicho lugar: el Muy Magnifgico Señor Liçenciado Fernando

Myranda, governador e justiçia mayor desta dicha ysla e de La Palma, e Juan de Meneses, e Juan Baptista de Arguij,o e dotor Juan de Fiesco, e Hernand Gonzales, rregidores de la dicha ysla, y, en presençia de my, Juan Lopez de Açoca, escrivano mayor del qabildo de la dicha ysla:

E luego, se platico sobre rrazon que, como (en) otros cabildos hechos e pasados en la çibdad, esta dicha (que) entre estas yslas andan armadas poderosas de françeses, haziendo dapño entre estas yslas, e an saltado en el puerto prinçipal de la ysla de La Palma, e saqueando e quemado la çibdad de La Palma. E la artilleria que esta ysla tiene en este puerto de Santa Cruz, está en grande rriesgo e peligro. E platicando el rremedio que para ello conviene, dixeron que de debia hazer en el dicho lugar, un baluarte del altor que convenga, continuando dende donde se acaba la muralla que esta hecha a la parte de la hermyta de Nuestra Señora de la Consolaçion, (y) de allí, a

4 Tachado: Lo.

5 Tachado: Salvador Rrodrigues.

${ }^{6}$ A su vez, se notifica al Cabildo de Gran Canaria.

7 Las casas, próximas a la artillería, ocluyen el ángulo de cobertura de su fuego. 
esgonçar ${ }^{8}$ hasta junto a la calle que va deste lugar a la dicha hermyta, a donde se señalo al presente, que se hizo un hoyo e fue puesto un mojon por Francisco Merino, cantero. E dende el dicho hoyo, vaya el dicho baluarte derecho $\mathrm{a}^{9}$ açia donde esta el solar que Diego Diaz tiene a tributo del Monasterio del dicho Espiritu Santo ${ }^{10}$, e antes que lleguen a la dicha pared del dicho Diego Diaz, (a una) distançia de ${ }^{11}$ doze pies, e dende allí, se atraviese al baluarte que esta hecho a la parte de la mar, 10 Vuelto por manera que entren e se yncluyan dentro deste sitio, las casas que al presente conpro el conçejo de Gonzalo Martyn, e las casas de Elvira de Parraga, e de Francisco de Cabrejas, e de la muger de Juan de Aguirre, $\mathrm{y}^{12}$ parte del almazen de Juan Pacheco, ${ }^{13}$ e que luego se ponga esto por obra. E para ello se aperçibio el dicho Francisco Merino, cantero, e los demas ofiçiales que ay en la çibdad e peones para ello, de manera que se haga con toda brevedad. Que se haga por ser cosa tan convinyente y nesçesaria, e que se conpren las dichas casas de sus dueños de los propios del qabildo. Y (que) el (muro de) dicho baluarte tenga ocho palmos de grueso, e del altor que les pareçiere, con sus cavalletes de cal encima ${ }^{14}$. E ansi lo probeyeron e mandaron, de lo qual son testigos: Francisco Solorzano del Hoyo, e el liçenciado Bartolome de Fonseca, e Diego Perez Lorenço.

\section{Rúbricas: Hernando/ Myranda, Juan de Aguirre, Pedro de/ Trugillo}

${ }^{8}$ Unirse y girar.

9 Tachado: Enfrente.

${ }^{10} \mathrm{La}$ Consolación pertenece al monasterio del Espíritu Santo, de la orden de San Agustín.

11 Tachado: Beynte.

12 Tachado: El almazen.

${ }^{13}$ Las escrituras de compraventa de estos inmuebles se encuentran entre los papeles sueltos del escribano Juan Azoca del Archivo Municipal de La Laguna, Fondo Antiguo, Sección I, con las foliaciones: Casas de Gonzalo Martín, labrador, y Leonor Mateos, su mujer, el 30 de julio de 1553: 1104 Recto-1106 Vuelto (foliación del Archivo 1128 Recto-1130 Vuelto). Estas casas fueron compradas en su momento a Cristóbal Núñez, vecino de Santa Cruz, y lindaban con las casas y corrales de Francisco de Cabrejas, vecino de Gran Canaria. Existe entre esos papeles sueltos referencia a la donación de unas casas de Elvira de Párraga a su sobrina, Ana Gonzáles, hecha ante Luis Sánchez, escribano público de Santa Cruz, de la que se hizo un traslado o copia, por Francisco Márquez, escribano público, que está en este registro, de lo cual quería tener constancia el Cabildo, pues Elvira de Párraga tenía en Santa Cruz, junto al baluarte, varias propiedades juntas: 1220 Recto-1223 Vuelto (foliación del Archivo: 1154 Recto-1157 Vuelto). Las casas donadas a Ana Gonzáles son las incorporadas al baluarte: $1123^{1}$ Recto- 1124 Vuelto (foliación del Archivo: 1158 Recto-1159 Vuelto) 13 de abril de 1554 .

${ }_{14}$ En los mismos papeles, se concierta el contrato para la adquisición de 50 cahíces de cal regada con Hernán Ramírez: 1214 Vuelto-1216 Vuelto (foliación del Archivo: 1148 Vuelto-1150 Vuelto. 
E luego, los señores rregidores dixeron que, con el ofiçial que a de faser la obra, an visto el dicho sytio de que en el capitulo anterior deste se haze mención, e pareçe que el sitio queda corto e no bien traçado, porque donde sobre este tobar ${ }^{15}$, el dicho baluarte a pasar veynte o veynte e çinco pies mas adelante de lo que esta señalado, quedaria el sitio mas en quadra, y estaria dentro un pedaço de plaça que queda de fuera. E para ello, conviene que se tome vn pedaço de corral de la casa de Diego Diaz ${ }^{16}$ e una sylla baxa que esta 11 Recto a la esquina de la dicha plaça, e otro pedaço del almazen de Juan Pacheco, que su pareçer (es) que se tome el dicho sytio e pedaço, e se pague por ello a sus dueños de propios lo que justo sea. E piden al Señor Gobernador se junten con ellos, pues que es cosa tan conviniente y nesçesaria para defensa deste puerto e ysla, e defensa del artillería. E luego, el Señor Gobernador dixo: ${ }^{17}$ que atento (a) que todos los señores rregidores son conformes en ello, que se juntan con su boto e parecer, queriendolo dar sus dueños por su boluntad. ${ }^{18}$

E despues desto, en veynte e ocho dias del mes de agosto, e del dicho año, estando los señores Justiçia e Rregimyento desta dicha ysla en su Cabildo e ayuntamiento, segund que lo an de uso e de costunbre ${ }^{19}$

E luego, se acordo e mando, que oy, despues de comer el Señor Gobernador con los señores Juan Baptista de Arguijo e Dotor Juan de Fiesco, Rregidores, vayan al lugar de Santa Cruz e probean hasta donde a de yr la obra del $^{20}$ valuarte que se haze en ${ }^{21}$ Santa Cruz, e por donde lo ordenaren, fagan los ofiçiales la dicha obra, para lo qual se les da

15 La grafía parece indicar tobar.

16 Papeles sueltos del escribano Juan Azoca del Archivo Municipal de La Laguna, Fondo Antiguo, Sección I. Cocina, horno y corrales de las casas de Diego Díaz, alcalde, que tenía alquiladas a tributo del monasterio del Espíritu Santo, el 20 de noviembre de 1553: 1213 Recto-1214 Recto (foliación del Archivo: 1147 Recto-1148 Recto); el 29 de diciembre de ese año -antes del cómputo gregoriano, era considerado ya 1554-, un grupo de frailes afianza dicho contrato: 1217 Recto-1218 Recto (Foliación del Archivo: 1151 Recto-1152 Recto).

17 Tachado: Que lo.

${ }_{18}$ Se hace donación de dichas propiedades al Cabildo.

19 Espacio de unas tres líneas en blanco.

20 Tachado: Muelle.

${ }^{21}$ Tachado: Esta. 
poder cunplido en forma.

11 Vuelto

E despues de lo susodicho, en este dicho dia, e mes, e año susodichos, el dicho Señor Gobernador, con los señores Juan Baptista de Arguijo e Dotor Juan de Fresco, rregidores, fueron al dicho lugar de Santa Cruz e vieron la dicha obra del valuarte que agora se fase. $\mathrm{E}$ ordenaron e mandaron que la dicha obra vaya prosiguyendo como agora va, hasta llegar doze pies antes de llegar a la pared que esta pegada a la casa de Diego Diaz, e dende allí, en quadra para baxo, a dar con la pared de los corrales de la casa de Diego Diaz, e dende alli abaxo, por el almazen de Juan Pacheco, al dicho baluarte, a dende quedo senalado por Francisco Merino, cantero. E ansy quedo acordado.

Rúbricas: Hernando/ Myranda, Juan Batista/ de Arguijo, Dotor/ Fresco

E despues desto, en viernes quinze dias del mes de setienbre, e del dicho año de myll e quynientos e çynquenta e tres años, estando los señores Justiçia e Rregimyento desta dicha ysla en cabildo e ayuntamiento:

E luego, se platico sobre rrazon que en el puerto de Santa Cruz se a hecho una plaça con su baluarte, para defensa del dicho puerto, a cabsa de las guerras que ay entre el Emperador e Rrey, Nuestro Señor, y el Rrey de Françia, e sus subditos e vasallos, e que muy a la continua, son visitadas estas yslas de las armadas de los dichos subditos del Rrey de Françia. E, porque la dicha plaça es bastante 12 Recto defensa para el dicho puerto, e se vaya acabando -que queda poco para se acabar-, acordose que se haga en el dicho puerto una fortaleza de la bondad, e tanmaño e manera ${ }^{22}$ que les parezca que convenga. E que vayan mañana, despues de comer, el Señor Gobernador con todos los señores rregidores, para que lo bean e determynen como se a de hacer, e (que) se hallen presentes las personas que les pareçiere que mas dello pueden saber, para que mejor se açierte la traça dello.

Bajada al ${ }^{23}$ Santa Cruz

E despues desto, en treynta dias del mes de otubre, año dicho, estando los dichos señores justiçia e rregimyento en su cabildo e ayuntamiento:

22 Palabra de difícil interpretación.

${ }^{23}$ Posible interpretación. 
E luego, el Señor Juan ${ }^{24}$ que ${ }^{25}$ Meneses, rregidor, dixo: que por su qabildo esta ordenado e mandado que se haga una torre en el lugar de Santa Cruz, para defensa desta ysla, atenta la grand nesçesidad que della ay, a cabsa de las guerras que ay entre el Emperador e Rrey Nuestro Señor, e (el) Rrey de Françia, e sus subditos e vasallos, e que de cada dia andan françeses entre estas yslas, haziendo 12 Vuelto dapño, que pide e rrequyere a los señores justiçias e rregidores que esten presentes, (y) que luego, con toda brevedad, se ponga ansy por obra. E lo pide por testimonyo.

E luego, los señores Justiçia e rregimiento dixeron que ansy se haga, e que porque esta obra no se puede hazer sin cal, e no la ay en esta ysla, que se de orden (y) conçierto $^{26}$ se trayga la dicha cal para lo poner por obra.

E luego, se cometio al señor Dotor Juan de Fresco, rregidor, para que se conçierte con algunas personas, que traigan dende Canaria al puerto de Santa Cruz, çinco o seys nabios de cal en piedra para la dicha obra, e se conçierte en el mejor preçio que pudiere. E la qual se conçertare, se dé por ello libramyento libramiento (sic) en el Mayordomo del Qabildo, para que lo pague de propios. E que aya toda diligencia e brevedad.

E despues desto, en seys de novienbre de IUdLIII ${ }^{27}$ años, estando los dichos señores justiçias e rregimiento en su cabildo e ayuntamiento, segund que lo an de uso e de costunbre, los dichos señores Justiçia e rregimientos dieron su poder cunplido al Dotor Juan de Fresco, rregidor, para que se puedan conçertar con los cabuqueros ${ }^{28}$ que se espiten, ${ }^{29} \mathrm{y}$ den para la obra de la fortaleza de Santa Cruz toda la canteria e piedra que fuere nesçesaria, e prometer por ello el preçio que le pareçiere a pagar, a los plazos e tiempos, e como a el le paresçiere, e hecho el concierto, pongan luego mano en ello, e se les paguen de propios lo que por el fuere conçertado, para lo qual le davan e dieron poder cunplido, con sus ynçidençias e dependencias, emergençias, amexidades e conexidades ${ }^{30}$.

E despues desto, en veynte dias del dicho mes de noviembre, del dicho año, estando los dichos señores Justiçias e rregimiento en su cabildo e a-

${ }^{24}$ Tachado: De Párraga, regidor de.

25 SIC: de.

${ }^{26}$ Contracción interpretada como concierto.

271553

${ }^{28}$ Palabra canaria: Picapedrero, cantero.

29 Apresuren.

30 Con todos los procesos anexos que pudiere conllevar. 
yuntamyento, es a saber: el dicho Señor Gobernador Hernando Myranda, e señores Juan de Aguirre,

e Pedro de Trujillo, e Anton Fonte, rregidores, luego se platico sobre

13 Recto

rrazon que este año pasado las armadas françesas ${ }^{31}$

[...]

\section{Recto}

E despues desto, en primero de dizienbre, año dicho de myll e quinientos

e çinquenta e tres años, estando los dichos señores justiçia e rre-

gimyento en su cabildo e ayuntamiento, segund que lo an de uso e de costunbre,

$\mathrm{y}$ en presençia de my, el dicho escrivano, luego se acordo e mando

que el domingo primero venydero, vayan con el Señor Gobernador

e señores rregidores con los ofiçiales e personas

que quisyeren yr, para dar orden a dónde e cómo

se a de haser la torre de Santa Cruz, e que se hallen a ello

presentes los capitanes, e que se vayan el domyngo de

mañana, despues de oydo mysa, porque ay opi-

niones que no es lugar convinyente a darse, se

señaló.

15 Recto

E despues desto, en tres dias del dicho mes de noviembre ${ }^{32}$,

e del dicho año de myll e quinientos e çinquenta e tres años, fueron

al lugar de Santa Cruz el dicho señor liçenciado Myranda, Gobernador desta

dicha ysla, e los señores Pedro de Trugillo e Juan de Meneses,

e Dotor Juan Fiesco, rregidores, e el liçenciado Francisco Bartolo-

me de Fonseca e Francisco Solorzano del Hoyo, capitanes, e el

padre Fray Pedro Grimon, prior del monasterio del Espiritu

Santo, e Francisco Coronado, e Juan Ortiz de Gomeztegui,

e Luys Perdomo, e Francisco de Rrojas, escrivano publico, e otras

muchas personas, asy de los barrios de la çibdad, como del lugar de

Santa Cruz. E platicaron dónde e cómo conviene que se

haga una fortaleza en el dicho lugar para defensa de la dicha ysla,

e bieron por vista de ojos la plaça çercada de baluarte

que esta hecha en el dicho lugar, e el sitio donde se dize que

conbenya haserse la dicha torre. E asy mismo, bieron por

vista de ojos, el sitio que esta junto a la hermyta de Nuestra Señora

de La Consolaçion, en donde ansi mysmo dezian algunas

personas que se podia hazer la dicha torre. E abiendolo

visto, e platicado sobre ello, se acordo que se haga una fortaleza

junto a la plaça que esta hecha de baluarte, en el dicho lugar, entre

31 El resto del folio está en blanco, así como la primera mitad del folio 14 Recto.

${ }^{32}$ Se interpreta un error, siendo el mes correcto diciembre. 
la dicha plaça e baluarte della, y la mar, a donde esta una laja entre la caleta e el muelle. Que tenga çiento e veynte ocho ${ }^{33}$ pies de cunplido azia la mar e çient pies de ancho, e que esto quede sin el grosor de las paredes, que a de ser de mas desto. E que tengan de grueso la çerca dello ${ }^{34}$ diez palmos de vara, e que las troneras sean, que tengan por la parte de dentro çercado lo mas que se pueda, segund el grandor de la artillería, e que por la parte de fuera sea rrasgada ${ }^{35}$ por todas quatro partes, de manera que por la parte de 15 Vuelto fuera tenga el mayor anchor que se pueda, e que estas troneras sean de la primera andana. E que para la segunda andana, ayan de poner el enmaderamyento de azeviña e barbusano, e los pilares de ${ }^{36}$ canteria rrezia. E que para las troneras se hagan sus portenolas ${ }^{37}$ de la banda de fuera, que sean de barbusano, para que se puedan çerrar cada que convenga. E que aya de aver tres andanas de artillería.

E que ansi, el sobrado de la segunda andana como de la terçera

Andana, tengan, el primero suelo de ladrillo, e luego se ormygonen tomo; $;^{38}$ e ençima del ormigon, otro asyento de ladrillos. E que para el primer suelo de terrapleno que se le ubiere de da,r para el primer suelo dello, se vea la altura que convenga, de manera que la mar, al tiempo de las aguas bravas, no entre por las troneras e haga dapño.

Otrosy, que aya de altura de la primera andana para la segunda, hasta la segunda catorze palmos de vara, que son tres varas y media de medir.

Y de la segunda andana hasta la ${ }^{39}$ tercera, que tenga el mysmo altor. Yten, que desta terçera andana, que a de ser el caballero ${ }^{40}$ para arriba, aya de tener la pared tanta altura como un onbre.

$\mathrm{E}$ que tengan sus saeteras.

Y desta manera quedo acordado e conçertado, en presençia de todos los señores de suso declarados e de otras personas que se hallaron presentes. T estando presentes Francisco Merino

${ }^{33}$ La grafía parece indicar ocho.

${ }^{34}$ Tachado: Ocho pal-.

35 Abierta.

36 Tachado: Palos.

37 Portañolas: Cañoneras, troneras.

${ }^{38}$ Bien hormigonado. Interpretación de la grafía.

39 Tachado: Segunda.

${ }^{40}$ Grafía interpretada como caballero: Obra de fortificación defensiva, interior y bastante elevada sobre otras de una plaza, para protegerlas mejor con su fuego. 
e Juan Diaz, albañy, e Gaspar Diaz, e Geronimo Diaz e otros.

Rúbricas: Hernando/ Myranda, Pedro de/ Trugillo, Francisco de Me/neses, Dotor/

Fiesco

16 Recto

E despues desto, en viernes doze dias del mes de

Enero, e del dicho año myll e quinientos e çiunquenta e quatro ańos,

se juntaron los señores Justiçia e rregimyento desta dicha ysla

en su Cabildo, segund que lo an de vso e de costunbre, es a saber:

el dicho Señor Liçençiado Juan de Myranda, Gobernador desta isla, e

los señores Juan de Aguyrre e Pedro de Trugillo, e

Juan de Meneses, e Juan Baptista de Arguijo, e Anton Fonte, e

Dotor Juan de Fresco, rregidores de la dicha ysla, e Francisco

Perez de Vitoria, jurado de la dicha ysla, e Anlonso Bazquez

de Naba, personero della, y en presençia de my, el dicho escrivano,

luego los dichos señores justiçia e rregimyento, dixeron que

muchas vezes en este cabildo se avia platicado quan

convinyente y nesçesario hera que se hiziese un

cuvelo o mas en el puerto de Santa Cruz, e otros

pertrechos para la defensa de la ysla, e convenya poner-

lo por obra. Acordose que mañana sábado, bayan

alli los dichos señores justiçia e rregimyento e los

demas vezinos que quisyeren yr, e sea pre-

gonado publicamente por las plaças de como an de yr

manana a lo susodicho, e que todos los becinos que

quisyeren yr, se vayan alla para dar a cada uno

16 Vuelto

su paereçer de lo que ara, (y) de lo que se deba hacer.

E ansi quedo acordado e conçertado.

E despues desto, en este dicho dia, e mes e

año susodichos, en la Plaça de Nuestra Señora

de los Rremedios desta çibdad, e por boz

de Lope Diaz, pregonero, a alta boz fue apre-

gonado lo susodicho, estando presentes muchas

personas, de lo qual son testigos Bernardino de

las Cuevas, Mayordomo del Qabildo, e Juan Ortiz de

Gomeztegui, e Luys de Almonte e

otros vezinos de la dicha ysla.

Acordose en Santa Cruz, que agora ante todas cosas, se haga

un cubelo ${ }^{41}$ en el dicho baluarte, e çe ara junto a la

calle que va a la hermyta, e que sea de tres andanas e

del anchor e grosor que les paresçiere, de como de alli

${ }^{41}$ Tachado: Çercado. 
se pueda sojudgar el canpo de açia la hermyta; e hecho, se hara otro abajo, a la laja, e se bera

del grandor que a de ser despues que este todo hecho.

17 Recto

En sabado treze de enero, año de myll e quinientos e çinquenta e quatro años, fueron al lugar de Santa Cruz el señor Gobernador Hernando Myranda, e señores Juan de Aguirre e Pedro de Trugillo, e Juan de Meneses e Dotor Juan de Fiesco, rregidores y en presençia de my, el dicho escrivano

[...]

17 Vuelto

Otrosi, fueron a ver por bista de ojos todo el rrededor del baluarte del dicho puerto, ${ }^{42}$ para determynar donde e como se podran haser los cubelos que otras vezes se avia platicado. E aviendolo visto, les pareçio que el lugar mas convinyente para haser uno de los dichos

18 Recto

cubelos hera de la calle que va del lugar a la hermita de Nuestra Señora de la Consolaçion, e de alli para abaxo, açia la mar, pegado al dicho baluarte. E que les pareçio que avia de ser de veynte e çinco pies de hueco, e que hecho este cubelo, ${ }^{43}$ pues es el mas nesçesario, se vera a donde conviene que se hagan los demas.

Otrosy, dixeron que una casylla que esta alli junto, que diz que es de Sancho de Salazar, porque haze grande estorvo, asi al baluarte como al cubelo que se a de hacer, ${ }^{44}$ acordaron que se derrive e allane todo aquel sitio, e se pague al dicho Sancho de Salazar por ella lo que justo sea, e se conçierte con el primero ${ }^{45}$ que se derrive.

[...]

42 Tachado: E.

43 Tachado: Se ve.

44 Tachado: Que.

${ }^{45}$ Antes de. 


\section{Descripción y medidas de la fortaleza de Santa Cruz ${ }^{46}$}

\section{Recto $^{47}$}

En el lugar y puerto de Santa Cruz, que es en esta ysla de Thenerife, en tres dias del mes de mayo, año del Señor de mill y quinientos y çinquenta y siete años. El muy Magnifico Señor Liçençiado Juan Lopez de Çepeda, Governador e Justiçia Mayor desta dicha Isla e de La Palma, por sus Magestades, por presençia de mi, Juan Lopez de Açoca, Escrivano Mayor del Conçejo, e público uno de las del numero de la dicha Ysla, por sus Magestades, dixo: que mandaba e mandó a Sebastian Merino, maestre de la canteria, que luego mida en presençia de su merçed el terrapleno (superpuesto: e cuvelo) del dicho puerto, que por mandado de su merçed, agora se a hecho e haze. E lo que asi midiere, se ponga e asiente por auto, lo qual haga con juramento, que ante todas cosas haga. El qual le fue tomado en forma e de Derecho, e hizo la dicha medida. E la declaraçion que asi con juramento hizo, es esta que se sigue:

Primeramente, declaró el dicho Sebastián Merino, que tiene todo el terrapleno de cunplido, con los lienços de fuera, dozientos e dos pies. Otrosi, que tiene de ancho, con los dos lienços, quarenta y siete pies. Otrosi, que tiene el dicho terrepleno, de frontera a la vanda de la mar, en el peçon del suelo, dies y seis palmos de grueso, e las paredes van rremitiendo, e que tiene en lo alto, donde se acaba el parapeto del dicho terrapleno, siete palmos de ancho.

Otrosi, que tiene de altura el dicho terrapleno, de la vanda de la mar, dende el suelo, hasta do se acaba el parapeto y rremate de la obra, veynte y çinco palmos de alto.

Otrosi, paresçe ${ }^{48}$ que mucha parte de la dicha frontera esta labrada de canteria, y el dicho Sebastian ${ }^{49}$ Merino declaro con juramento, que tenia de altura, dende el suelo, hasta doze palmos de altura de la dicha canteria, y lo demás, hasta el rremate de la dicha obra, de manposteria, salvo la postrera hilada, do se acaba la dicha obra, (que) va asi mismo de canteria. 1 Vuelto Otrosi, que el dicho terrapleno y cubelo bate la mar, (y los) baña con la mar llena. E yo, el dicho escrivano, en presençia del dicho Señor

46 Esta carpeta contiene un documento de 1568, que se verá más adelante, en el que el alcaide Juan Sánchez de Zambrana propone una serie de cambios en la traza de la fortaleza, incluyendo un dibujo a mano alzada de dicha propuesta y varios bocetos de sendas perspectivas.

${ }_{47}$ Escrito hasta el final del folio 2 Vuelto en letra de molde, muy cuidada, se asemeja la corrección a la escritura Cortesana.

48 Similar a comparecer. Explica.

49 Tachado: Moreno. 
Governador y del dicho Maestre, vi batir la mar en el dicho cubelo e terrapleno. Otrosi, mediós ${ }^{50}$ el dicho Maestre lo que esta hasta agora labrado del cubelo, e declaro que tiene de altura hasta agora: veinte e un palmos, poquita cosa menos.

Otrosi, el dicho cubelo que tiene de grueso de pared alrededor, es a saber, en el peçon que es el prinçipio de la obra, dies y seis palmos de grueso, e que las paredes van rremitiendo para dentro, y que en el altura que agora esta, tiene onze palmos de medida de anchura.

Otrosi, medió el dicho Maestre, e dixo que tiene el dicho cubelo, por la parte de fuera, çiento y ochenta y un pies de rrededor.

Otrosi, que tiene por la vanda de dentro, que se entiende por el patio del dicho cubelo, çiento y treinta y çinco pies de rrededor.

Otrosi, que tiene de hueco el dicho cubelo, en la altura que agora esta, por la parte de dentro, quarenta y dos pies de quadra.

Otrosi, asi el dicho terrapleno hasta su parapeto y el dicho cubelo, hasta el altura que agora esta, esta todo terraplenado, e tu pido de piedra, e varro, e tierra e otros materiales.

Otrosi, esta enpeçado a labrar el muro e lienços que serca todo el sitio e plaça E declaró el dicho Maestre, so cargo del dicho juramento, que lleva de grosor nuebe palmos.

Los quales dichos pies e palmos de barro, me dixo ser de marca, es a saber, quatro palmos la vara de medir, e tres pies la dicha vara de medir ${ }^{51}$.

Otrosi, esta hecha una puerta para el dicho cubelo e terrapleno, que tiene una puerta hecha de madera rrezia, con sus batientes

2 Recto

e puntas de hierro, con otra conpuerta que cahe sobre çiertas puntas de hierro, para alçar por torno.

Otrosi, esta en el dicho sitio e plaça, a la vanda de la tierra, para defensa de la dicha fuerça, otro cubelo de manposteria de piedra e cal, e troneras de canteria. E que esta es la verdad, so cargo del juramento que hizo, e firmolo de su nombre el Liçençiado Çepeda (e) Sabastian Merino.

3 Recto $^{52}$

[...]

5 Recto

Al tiempo (que) se hizo el terrapleno de la fuerça de Santa Cruz,

50 Midió.

51 En definitiva, 1 Vara = 4 Palmos = 3 Pies. Los pies eran denominados pies españoles antiguos. Las medidas corresponden, según la fuente digital https://alcazaren.com/node/250: 1 vara= $0.835905 \mathrm{~m} ; 1$ pie o tercia $($ de vara $)=0.278635 \mathrm{~m} ; 1$ palmo o cuarta $($ de vara $)=0.20897625 \mathrm{~m}$; $\mathrm{y}$ de ello, se deduce que $1 \mathrm{pie}^{2}=0.077637463225 \mathrm{~m}^{2}$.

${ }_{52}$ Las siguientes páginas son el borrador de lo escrito. 
avia en esta Ysla poca artilleria e pequeña, que solamente avia el tiro pedrero San Miguel y dose sacres. El anchor que se le dio al dicho terrapleno es poco, e poco cumplimyento para la dicha artilleria. La esperiençia muestra que conviene que aya mas cantidad de artilleria gruesa e mas terra pleno.

Otrosi, a cabsa de ser el terrapleno angosto, quando juegan con las pieças grandes, en espeçial con las dos culebrinas, dan grande coçto que es cabsa que las caxas e rruedas se quiebren y desbaraten, ${ }^{53}$

para rremedio de lo que me convernia, ${ }^{54}$ que el dicho terrapleno se ensanchase para la parte de dentro hasta diez pies mas. (Superpuesto: Y con esto,) ${ }^{55}$ juega mejor e mas seguro la dicha artilleria.

Yten, todo el terrapelno esta descubierto, que por la banda de la hermyta se señorea toda (la fortaleza), en tal manera que una dozena de arcabuzeros que se pusiesen a la dicha hermyta, ninguna persona podra estar en el terrapleno del artillería, (lo) que es muy grande ynconviniente. Y el mejor rremedio que para esto podra aver, es que a la parte de la caleta, podran correr mas el terrapleno, todo lo que pudiere, hasta el agua, e que esto sea mas alto que el que se a hecho, en el altor del cuvelo, poco mas o menos, y este podra tener $\mathrm{el}^{56}$ anchor que convenga para las culebrinas. Y 5 Vuelto subir el lienço de $1 a^{57}$ parte de la hermyta, de manera que la gente este segura. E dende este terrapleno, se podra señorear toda la mar e la tierra, aviendo buenas pieças de artillería, en especial si la hermyta se quyta de alli y se pasa a otra parte que no haga estorbo. $Y$ con esto, se podra rebasar el ensanchamiento del terrapleno que se a hecho, porque las culebrinas e pieças grandes podran estar en el terrapleno nuevo. Y San Miguel e los sacres, e la otra artilleria en el que esta hecho ${ }^{58}$. Y rreçibese mas benefiçio de hazerse el dicho terrapleno nuevo en la caletilla, que da por

53 Tachado: Otrosi, los petriles de/ dicho terrapleno son altos y el suelo baxo.

${ }^{54}$ Convendría.

55 Tachado: por no/ rromper el lienço del petril, se podran subier el galibo de/ dicho terrapleno doce palmos o lo que pareçiese, porque la dicha/ artilleria se pueda servir con dos caxas que sean/ mas seguras e amables, e mas manuales.

56 Tachado: Alto.

57 Tachado: Haz.

58 Tachado: con sola-/mente alçarle el suelo doce palmos poco mas o menos/ como es dicho. 
cava $^{59}$ del, $e^{60}$ nadie podra pasar por aquella banda, que le da fuerça e calidad. Y también, con este terrapleno nuevo se abriga el viejo para que no rreçiba dapno de la parte de la hermyta, que esta dicho, y se le quyta el padrastro ${ }^{61}$ que tiene.

Yten, asi este terrapleno que esta hecho mas afuera y que llegara a la mar, señorearase de alli mas la mar e la tierra, e en especial, a la parte de Blas Diaz, que es la parte donde mas conviene. Pero, como la hoz ${ }^{62}$ del esta hecha de canteria labrada e tan rrezia e costosa, es ynconviniente grande, y tambien porque el cuvelo nuevo, que es pieça tan principal, no sirbira. Y por esto, se sufrira que este donde está, en especial con los rremedios dichos, sin deshazer semejante obra.

Demas de lo susodicho, convernia un almazen grande donde esten las armas, e muniçion, e polvora e lo de6 Recto mas necesario, e que se suviesen donde el terrapleno. Y al hazerse el terrapleno nuevo en la parte dicha, se podra haser el dicho almazen pegado a el. Yten, el aposento del alcaide no esta al presente en lugar decente. Vease si estara bien pegado al lienço e a la entrada de la fortaleza.

Yten, converna hazerse puerta como convenga para fortaleza, pero mientras ay en ella obras, es ynconveniente que estorbará la entrada de carretas e otros serviçios de la obra.

En uno de noviembre 1566 años, el Señor Governador liçençiado Juan Vélez e el Señor Pedro de Ponte, Capitan Balcarçel en Santo Cruz, e Pedro de Vergara, e Francisco de Coronado, e Juan de Asoça, con otras personas, e con Francisco Gonzales e Gonçalo Yanez, albañil, fueron a la fortaleza e se vido el terrapleno e lo demás, e les pareçio que salga el terrapleno açia la caletilla ${ }^{63}$ e se haga un cavallero ${ }^{64}$ que este catorze

59 Foso.

${ }^{60}$ Tachado: Ny.

${ }_{61}^{61}$ Dominio.

${ }^{62}$ Angostura.

${ }_{63}$ Tachado: E sea mas alto que el que se a hecho catorze palmos.

${ }^{64}$ Obra de fortificación defensiva, interior y bastante elevada sobre otras de una plaza, para protegerlas mejor con su fuego. 
palmos mas alto que el terrapleno:

Digo que se mande haser un caballero, que suba mas de

el dicho terrapleno doze o catorze palmos, por-

que con esto, se dava lugar donde el artilleria prin-

çipal pudiese estar. E demas desto, se quyta

el padrasto que tiene del suelo donde esta la ermita.

Digo que es en viernes ocho de noviembre, en cabildo, y en jueves

antes, se proveyo lo de suso.

\section{SOBRE LA EVOLUCIÓN DE LA CONSTRUCCIÓN DE LA FORTALEZA Y EL INFORME QUE ha de llevar don Alonso Pacheco Criado, a la Corte}

25 Vuelto +

En la noble çibdad de San Cristobal, que es en la ysla de

Thenerife, en viernes, tres dias del mes de

hebrero, año del nasçimiento de nuestro Salvador

Ihesucristo de myll e quinientos e çinquenta e nueve ańos, fueron

juntos en cabildo: el Muy Magnifico Señor Capitan Hernando

de Cañizares, Governador desta ysla de Thenerife e de la

ysla de La Palma, por su Magestad; y el señor Diego Broza de

Rreynoso, su thenyente; y los señores Pedro de Truxillo, Dotor

Fresco, Bachiller Alonso de Llerena, el liçenciado Bartolome de

Fonseca, Francisco Perez de Bitoria, Juan de Valverde, rregidores

desta isla; e por presençia de mi, Francisco de Rrojas,

Escrivano Mayor del Cabildo y Publico desta dicha ysla.

E luego, los dichos señores Justiçia e rregimyento dixeron:

Que porque Don Alonso Pacheco, vezitador por su

Magestad, e nonbrado para las fuerças, y defensas, e gente de

guerra desta isla, e otras cosas, esta al presente en esta

ysla para hazer y efetuar lo que por su Magestad esta

mandado, y conviene que se haga y efetue lo en la Çédula

Rreal contenido. E para lo hazer y efectuar, acorda-

ron e mandaron que mañana sábado, vayan el

Senor Governador y todos los señores rregidores con el dicho

Don Alonso Pacheco, a ver e vesitar la fortalesa del

puerto de Santa Cruz, y la artillería y muniçion, y los de-

mas pertrechos della, y que el Domingo siguiente se haga rreseña general en esta

çibdad de todas las vanderas y capitanias della, y de su comarca y lugares

sercanos a esta çibdad. Y en lo que toca a los demas lugares y fuerças de la isla, probeheron y señalaron en este cabildo, las personas que para hello se hallavan presentes.

26 Recto 
E despues de lo susodicho, en este dicho dia, ${ }^{65}$

tres dias del dicho mes de hebrero, e del

dicho año, el dicho Señor Governador dixo: Que

porque esta probeydo por cabildo de yr

manana sabado a vesitar la fortaleza,

e artillería, e munyçion que en ella ay, estando

presente el dicho Don Alonso Pacheco, como su Magestad

lo manda, que para hazer rreseña e alarde

de la gente de guerra que ay en esta çibdad

y lugares comarcanos de junto desta çibdad, que se ha de haser el domingo, que seran çinco

dias deste mes, mando ser notificado a los capitanes de guerra desta çibdad, que para el dicho

domyngo esten presentes e paresçidos, con

sus vanderas e gente que cada uno de

ellos tiene por lista e nomyna, para que se

faga la dicha muestra e rreseña de gente,

presente el dicho Don Alonso Pacheco, e que todos ven-

gan con sus armas, y adereço e rre-

cabdo, para que se vean. E que nynguno dexe de salir

ny venir, so pena que se prosedera con-

tra ellos y cada uno dellos con todo rrigor.

[...]

27 Vuelto

E despues desto, este dicho dia, e mes e año,

dicho por my, el dicho escrivano, fue noteficado

el dicho abto de suso al dicho Luys Per-

domo, capitan de gente de cavallo

en persona, el qual dixo que esta presto de lo

conplir. Testigos: Guillen de Betancor

e Gaspar de Rrojas.

E despues de lo susodicho en este dicho dia, quatro dias del mes de hebrero, e del dicho año, los dichos señores Governador

e Pedro de Truxillo, e el Liçenciado Alonso de Llerena,

y el dotor Fresco, e el liçenciado Fonseca, e

e (sic) Francisco de Coronado, e Francisco Peres de

Vitoria, rregidores desta isla, juntamente

con el dicho Don Alonso Pacheco e presençia

de my, el dicho escrivano, fueron desta çibdad

al lugar e puerto de Santa Cruz, donde

${ }^{65}$ Tachado: E. 
esta fecha la fortaleza e terrapleno.

Y estando allí, en ella dentro, los dichos

señores Governador e rregidores, junta

mente con el dicho Don Alonso Pacheco,

dixeron que para que se vea toda la

obra e fuerça que esta fecha, e la que

28 Recto

falta de hazer para que se acabe e

quede perfeta, e ver lo que mas

conviene, fizieron pareçer ante si

a Francisco Merino, maestro mayor de

obras de canteria e geometria desta

ysla, e a Luys Hernandes, asy mismo maestre

de geometría, e a Diego Peres Lorenço,

e a Ynigo de Durango Vizcayno, que son

personas práticas, y espertas y en

tendidas en semejantes obras e he-

defiçios de fortalezas. E pareçidos, ${ }^{66}$

fue dellos por el señor Governador tomado

e rreçebido juramento por Dios e

por Santa Maria, e por las palabras

de los Santos Evangelios, e sobre la

Señal de la Cruz, donde pusyeron sus

manos derechas en forma de Derecho, que bien

e fielmente, syn arte ny engano, ni

pretemor, miedo, amenazas, yndu-

zimyento ny percabsa que sea, veran toda

la obra que esta fecha en el terrapleno

e cubelos, e çerca desta fortaleza.

E declararon el arte que tiene

y como estan fechos, e qué altor, e lon-

gor e anchor tienen, e quales falta

de fazer para estar acabada la dicha

fortaleza, e qué seria nesçesario

hazerse, e qué falta o hierro ${ }^{67}$ tiene,

para que se enmyende, de manera

que no les fuese nada de desir e

declarar, e que sy asi lo hizieren,

nuestro Señor les ayude donde sea que el

28 Vuelto

$66 \mathrm{Y}$ presentes.

67 Error. 
se lo demande, mal e caramente, como malos cristianos, los quales a la asoluçion del dicho juramento, dixeron 'Sí juro, e Amén'. Syendo testigos: Blas Lorenzo, e Diego Caravallo e Pedro Gomez.

/Terrapleno/ Despues desto, en este dicho dia, e mes, e año dicho, los dichos Francisco Merino, e Luys Hernandes, e Diego Perez Lorenço, e Ynigo de Durango, personas de suso nonbradas, e por se ver de los dichos señores Governador e rregidores, e Don Alonso Pacheco, en presençia de my, el dicho escrivano, vieron e anduvieron el terrapleno que esta en la dicha fortaleza, el qual mydieron e dixeron que tiene de conplido treynta e seys braças, e que tiene de ancho treynta pies, el qual si ben, e ven que esta en prençipiado sobre una laja junto e pegado a la mar, a la vanda del levante. E dende el simyento hasta la mytad del, esta fecho de canteria fuerte, e de alli arriba, de piedra e de argamasa. E por la vanda de la mar, ${ }^{68}$ tiene treynta palmos de altor. E de la vanda de tierra, tiene veynte palmos de altor. Y desta vanda esta fecho de piedra e de argamasa.

Otrosi, dixeron que han visto e ven, que junto del dicho terrapleno, ${ }^{69}$ a la vanda de ponyente, esta fecho un 29 Recto

/Cubelo/ cubelo, el qual esta fecho de la mysma obra de canteria e de argamasa del dicho terrapleno, e que tiene de altor, dende el suelo hasta donde agora esta fecha la obra, çinquenta palmos, en el qual cubelo, si ben, e ven, que esta un algibe para rrecojer agua, el qual esta fecho e labrado de cal y ladrillo, e es del mysmo altor del cubelo, e que tiene de anchor ocho palmos de çintel en rre-

68 Tachado: Tr.

69 Tachado: Es. 
dondo. Y el dicho cubelo tiene de gueco treynta e çinco pies. E de pared doze pies.

/Puertas/ del terra/pleno

Otrosi, dixeron que ven questa fecha

una puerta por donde suben al

terrapleno y cubelo, de piedra e de

argamasa, con sus puertas guarneçi-

das de hierro y una escalera por donde

suben, levadiza, con su cadena e torno,

para la subir. E tiene un rrastrillo por

de dentro, con sus puntas de hierro para

rresguardo de la puerta. E sobre la puerta,

las armas Rreales de la Ysla ${ }^{70}$.

/Cubelo/

Otrosi, dixeron que han visto, e ven que esta

fecho, otro cubelo a la vanda del Norte,

de piedra e cal, con sus troneras e dos

sobrados con sus vigas, y ladrillo por

tabla. E arriba de los dos soberados, esta

su pertil e sus almenas, e rremate

e troneras, e tiene de alto çinquenta

palmos poco mas o menos. E de anchor

tiene veynte e quatro pies. E las paredes

son de grueso de ocho palmos, antes

mas que menos, con sus puertas fuertes,

altas e bajas, para serviçio del dicho cubelo.

29 Vuelto

Otrosi, dixeron que esta fecha una çerca

de piedra e barro, que sirve agora

defensa rreparo de la artilleria que

esta en el dicho terrapleno que tiene de alto

veynte palmos con una puerta grande

${ }^{70}$ Es necesario precisar que hasta el momento no he encontrado documentación precisa que indique de qué escudo se trata. Según las aportaciones del historiador militar José Miguel Rodríguez Illescas, con la construcción de una fortificación nueva, se labra también un escudo de armas nuevo, por lo que probablemente el escudo que se incorporaría en la fachada del Castillo de San Cristóbal no sería el mismo. De la misma manera, por una parte, el escudo del cubelo de la fortificación podría tener la simbología del rey Carlos I (emperador Carlos V), pero la nomenclatura 'Armas Reales de la Isla' puede hacer referencia al escudo de armas que Juana I de Castilla, reina oficialmente hasta su muerte en 1555, otorgó a la Isla de Tenerife por medio de la Real Cédula de 23 de marzo de 1510. En cualquier caso, el escudo de la fachada del Castillo de San Miguel de Garachico tiene la simbología de Felipe II. 
para serviçio.

Otrosi, dixeron los dichos Francisco Merino,

e Luys Hernandes, e Diego Perez Lorenço, e Ynigo

de Durango, que para acabar de haser

la obra que falta en la dicha fortaleza,

terraplen, y cubelo, y muros, e otras

cosas, que conviene que se haga los rre-

paros e obras siguientes:

/Terrapleno/

Yten, que para que el dicho terrapleno

este perfeto e acabado en perfiçion,

e para que la artilleria pueda libremente

jugar en el, conviene y es neçesario

que se ensanche por la vanda de

tierra doze pies de anchor.

/Cubelo/

Yten, dixeron que para que el dicho cubelo

que esta pegado al dicho terrapleno,

quede bien fecho, e acabado, y en toda per

fiçion, es neçesario e conviene que

se acabe de hazer, y le faltaran

de subirlo çinquenta palmos poco

poco (sic) mas o menos. Y en el dicho cubelo

a de aver quatro troneras e una puerta

que cayga al terrapleno por la parte

de dentro, con su conpuerta e con su

escalera derecha o caracol.

30 Recto

/Los muros/

Otrosi, dixeron que se ha de hazer

un muro a la vanda del norte, que tome

dende el terrapleno que esta fecho, que

vaya derecho a la esquina de las casas

de Gaspar Rrodrigues, en el qual, conforme a la me-

dida que oy ellos an fecho, presentes el

dicho Señor Governador e señores rregidores, e Don Alonso Pacheco,

e de my, el dicho escrivano, a de tener treynta e

quatro braças de conplido, asy, sin esta

parte, como dende el dicho cubelo, a dar

derecho a la casa de Blas Lorenço, que

como dicho, tienen frente otro tanto con-

plido. Y por esta parte, el terrapleno

tiene de conplido treynta e ocho braças,

y a de tener el muro por estas dos partes,

de anchor diez palmos: es a saber, seys 
para el muro e quatro para anden. Y de altor, diez tapias de muro de la vanda del norte, y el muro de la parte del sur a de tener syete tapias. Y estos muros an de ser de piedra y cal. Y las troneras en ellos an de ser de canteria.

/Cubelo/ y puerta/

Otrosi, dixeron que se ha de hazer en el cabo del muro que viene dende el terrapleno a dar a la esquina de la casa de Gaspar Rrodriguez, un cubelo junto de otro cubelo que alli esta fecho, el qual a de ser de piedra e argamasa, e del alto del cubelo que alli esta fecho, con sus troneras. E, entre un cubelo e otro, se ha de hazer la puerta de la dicha fortaleza, de canteria, con puertas rrezias e fornidas. E la puerta a de ser con su 30 Vuelto buelta rredonda. $\mathrm{Y}$ ençima de la puerta, un rrastrillo de hierro que cayga entre las puertas. E dende este cubelo, a de yr un muro para la calle abajo, azia el Sur, a dar a la puerta de Blas Lorenço, a çerrar con el otro muro que a de correr dende el cubelo que esta a la vanda del Sur. ${ }^{71} \mathrm{Y}$ a de ser este serviçio de syete tapias en alto, con sus troneras de canteria e cal.

/Casas de aposento/ del alcayde/ Otrosi, dixeron que se a de hazer casas de aposento para el alcayde a la vanda del Sur, junto al terrapleno, que tenga sesenta pies de ancho, con su sala e palacio, e con su serviçio de cocina, e despensa, e chimenea, e hornos, e otro aposento para caballeriza, e donde este paja elevada e muniçion.

/Las casas que se/ an de conprar y/ quitar y hermi/ta/ Otrosi, dixeron que para hazer la dicha obra e murallas, es menester conprar

71 Tachado: T. 
las casas que estan junto de la fortaleza, a la vanda del Sur e del Norte, e quytar una hermyta que esta junto, por ser como son todo ello, padras$\operatorname{tros}^{72}$ de la dicha fortaleza.

Y que fecho lo susodicho, la dicha fuerça

e fortaleza quedará perfeta, e bien fecha e acabada, e defensible de enemigos, e donde se puedan rregojer los de la ysla para defender la dicha fuerça, e artilleria, e ofender dende ella 31 Recto a los enemigos que quisieren venyr a hazer algun daño. E, que con esto, no tiene ni avrá falta, ny ellos la syenten, ny tanpoco cosa que se aya de deshazer, fiziendo lo que dicho tienen. E que esto es su parecer, e lo que saben e se les alcança. $Y$ es la verdad por el juramento que fizieron. Rúbrica: Francisco/de Rrojas ${ }^{73}$

Despues de lo susodicho, en este dicho dia, e mes, e año dicho, los dichos señores Governador e rregidores, juntamente con el dicho Don Alonso Pacheco, en presençia de my, el dicho escrivano, vieron la munyçion e artilleria que tiene a su cargo el Señor Francisco de Coronado, rregidor e alcaide de la fortaleza, e se hallo en ella lo siguiente:

- Primeramente, dos culebrinas de metal, que dizen que pesan çiento y diez e seys quyntales, e tres arrobas, y diez e seys libras e media, en sus caxas e carretones chapeados de hierro.

- Yten, otra pieça de metal, como media Culebrina, que diz que tiene de peso veynte e çinco quyntales e quarenta libras, con su caxa e carretones, e dos candados, uno en la boca e otro en la çevadera.

${ }^{72}$ Lugar alto que domina una plaza.

73 Aunque la lógica nos dice que es el propio escribano quien rubrica el texto, la grafía de la firma no se asemeja a otras del mismo. 
31 Vuelto

- Yten, otra piesa de metal de la mysma suerte e tamaño, como la de antes desta, segund dixo el dicho Alcayde, con sus caxas e carretones, e dos candados, en la boca y en la çevadera.

- Yten, otro tiro de metal mas pequeno, como medio sacre, que diz que tiene doze quyntales e quarenta libras, con su caxa e carreton, e dos candados, uno en la boca y otro en la çevadera.

- Yten, otra pieça de metal como sacre, que diz que pesa veynte quyntales e tres arrobas, con su caxa e carreton.

- Yten, otra pieça de metal como un pedrero, llamado San Myguel, con su caxa e carretones, e un candado a la boca e otro en la çevadera.

- Yten, otra pieça de hierro colado, como medio sacre, con su caxa, e carretones, e candados en la boca y en la çevadera.

- Yten, rrascadores e limpiadores para la dicha artilleria.

- Yten, çinco pasamuros de hierro, los dos dellos encavalgados con sus caxas e carretones, e los demas para encabalgar, $\mathrm{y}$ todos con sus servidores.

- Yten, dos versos dobles, el uno con sus camaras e el otro con una camara ${ }^{74}$.

Son de hierro colado.

32 Recto

- Yten, una catalineta de hierro con su camara.

- Yten, otra catalineta de hierro con otra camara.

- Yten, quatro versos de hierro con sus camaras, e con çinco mosquetes de hierro.

- Yten, un quarto con vinagre.

- Nueve o diez qyntales de polvora en barriles.

- Pelotas en cantidad para la dicha artilleria.

${ }^{74}$ Tachado: de. 
- Quatro dozenas de saletas ${ }^{75}$.

- Siete bonbas de fuego de madera.

- Seys caños de metal.

- Tres baras de hierro.

- Una almadana.

- Un picon.

- Una sierra pequeña.

- Un sacapelotas.

- Dos açideras viejas.

- Quatro carretones de los versos con sus

caxas.

- La vandera de la fortaleza.

- Una tanbor.

4. Sobre las propuestas Que hace para la fortaleza el alCaide Juan Sánchez DE ZAMBRANA

1 Recto

Sobre la torre

Ylustres Señores

En este ${ }^{76}$ jueves 13 de Mayo 1568

Aunque de las tres de Rroma se me de la una, llevarla quiero como servidor y vasallo de su Magestad y alcayde de su fortaleza, al presente sometiendome a mejor juyzio que donde vuestra Señoria y esos señores Cavalleros están, y sus botos y pareser es lo asertado, e poco al caso harán el mio, para costa

de tanta calidad y cantidad la trasa que yo diere vuestra Señoria. Rreçiban mi deseo, que es en todo se sirva a su Magestad como Vuestra Señoria y esos señores lo an hecho,

y hazen, y harán sin falta, digo que a mi entender, la fortalesa para ser fuerte a de tener lo siguiente:

Lo primero, ver el suelo donde se a de hacer, y si del, se puede defender y ofender, porque donde quiera, se hara fuerte -y este suelo es la laja-. Lo segundo, que este donde mas alcanse la artilleria y de sonbra (a) puertos, y abras $^{77}$ y caletas. Y este a domo ${ }^{78}$ del pueblo, para que la fortalesa y su

75 Saetas.

76 Tachado: 11

77 Bahía no muy extensa.

78 Interpretado como 'controlando'. 
alcayde so jusgue todo. Y esto esta en la laja, a lo ultimo della. Lo terçio, es que los simientos sean fixos, porque no se pueda minar, y estos tienen la laja, que son los naturales que Dios hiso, e van a buscar los que saben de fuerças - y no los artifiçiales -, porque para los artifiçiales, por lo menos a menester mas de dos estados ${ }^{79} \mathrm{y}$ piedras mui grandes $-\mathrm{y}$ e dicho poco-. Y el costo de los simientos ahorra la laja con que se haze el terrapleno. Lo quarto, ver si ayi donde se haga foso y fuerte, para dalle mas ser, con su puente levadizo. Este foso esta a la entrada del terrapleno, donde por el, toda la fortalesa sera sercada de agua, y en el lienço dellas, sus troneras pequeñas cubiertas, que jueguen los bersos a tierra para ofender.

Lo quinto, para que sea muy señora de los navios y haga mas a sabor la punteria el artilleria y sus artilleros, es a la lengua de agua, donde con ella, por aquella parte, no teme tomarse ni perderse, porque la mar la defiende. Y todo esto esta y hallara vuestra Seńoria en la laja.

Lo sesto, que para que la obra hecha no se pierda y sirba solo el lienço de la mar deste terrapleno, se deshara en dos palabras ${ }^{80}$ y sirbira a los maestros para a la lengua del (a)gua hazer el terrapleno, (para) que sea mas ancho que este doze pies y mas. Y la tierra del, estara a comodo para ${ }^{81}$ el que se a de hazer a la lengua del agua, con dos portanólas ${ }^{82}$ para que se pueda correr por la barbacana, todo 1 Vuelto porque se hara fácil, y creo que los maestros diran lo que yo. Las primeras hiladas, de piedra labrada seca, y si quieziere vuestra Señoria que lleve por las junturas plomo, sera mejor, (superpuesto: y con sus gatos), y esto quando esten labradas las piedras todas, para quatro o çinco hiladas. Y todos los ofiçiales de la çibdad y ysla que lo entienden, con los maestros y dos conpañias del Sabsal y Tancoronte, y otra de la çibdad, que aquel dia ayuden, y asi la obra de vuestra señoria creserá, y su Magestad rreçibira serviçio y su rrepublica, de vuestra señoria, gran bien y descanso -dexo las otras labores de dentro e los otros lienços que an de correr, que vuestra Seńoria como lo demas tienen en su trasa y su omenaje, se hara quando fueren servidos. Esto es lo que me pareçe que haze al caso debaxo de lo arriba dicho. - Myo Ylustre Ayuntamyento, nuestro Señor prospere.

Rúbrica: Juan Sanches/ de Çambrana

79 Puede referirse a una medida de 7 pies, ya sea de ancho, de largo o de alto; a 49 pies cuadrados, o a séquitos. La interpretación más verosímil para los dos estados mencionados es 14 pies de alto.

80 Rápidamente.

81 Tachado: que.

82 Troneras, cañoneras. 


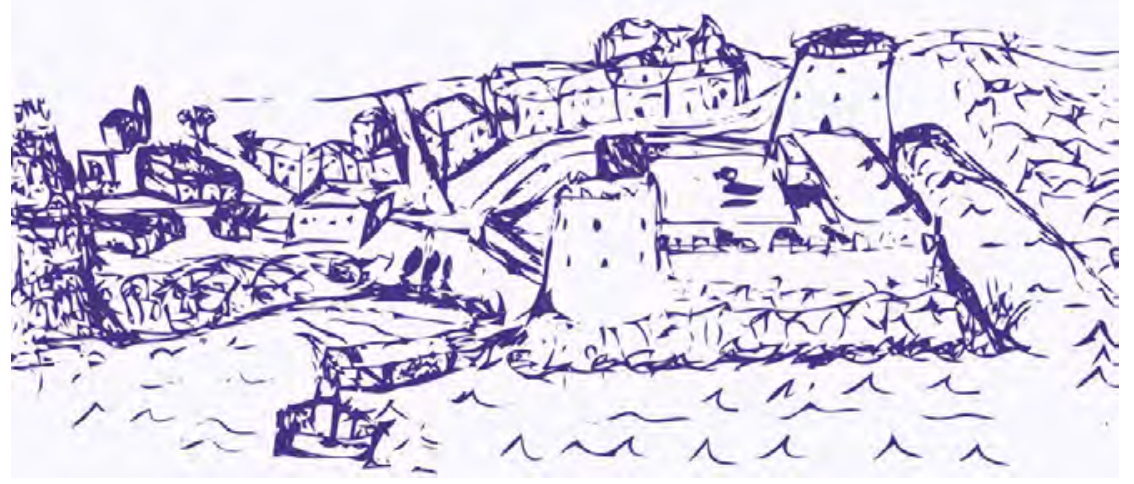

Figura 1: Boceto del lugar de Santa Cruz en torno a 1560. La interpretación parte del trazado urbano plasmado en el plano de Leonardo Torriani (Torriani, p. 74) con las pertinentes modificaciones edilicias.
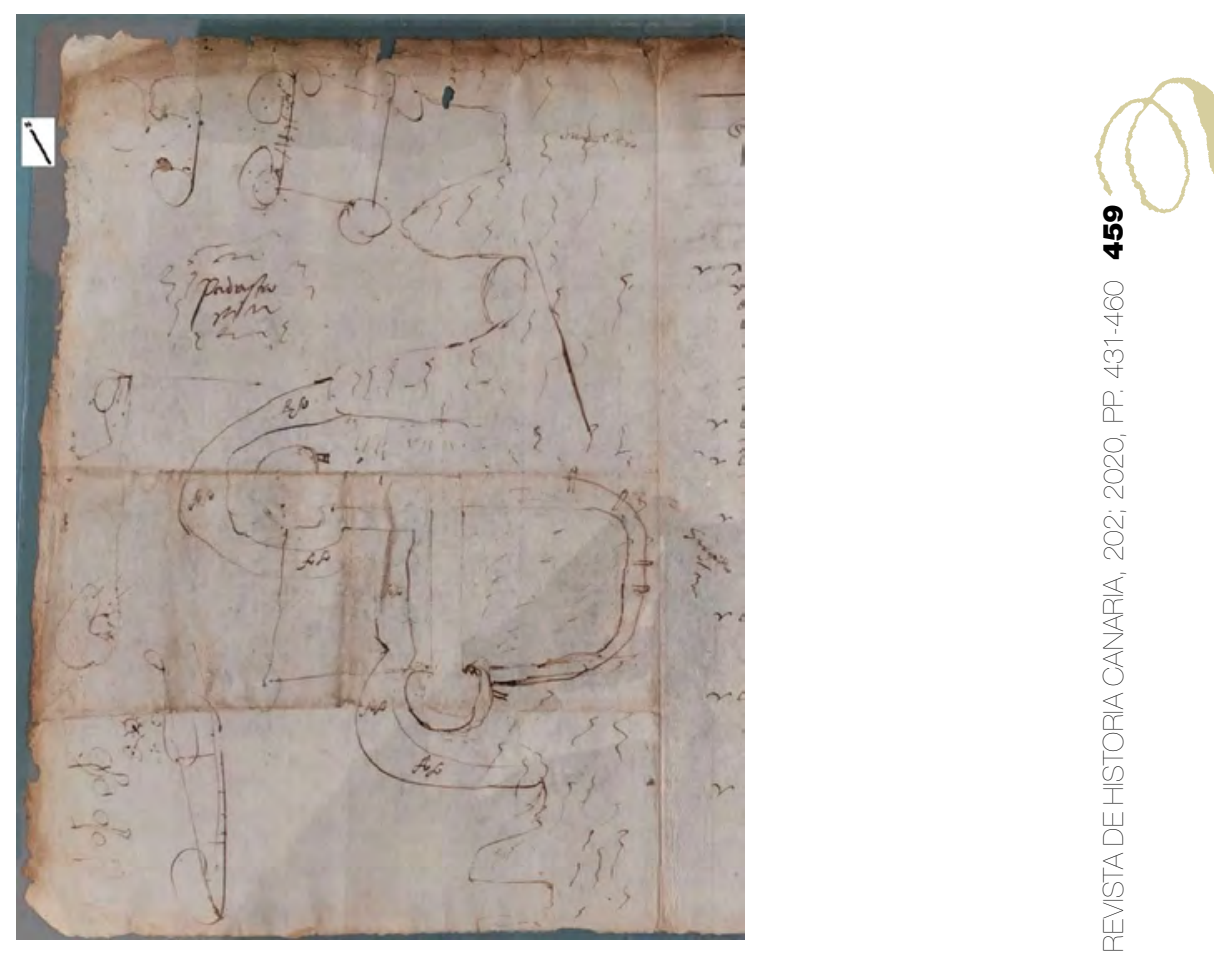

Figura 2: Boceto realizado por Juan Sánchez de Zambrana, correspondiente al folio $2 \mathrm{v}^{\mathrm{o}}$ del documento, con indicación del norte geográfico. 


\section{DOCUMENTACIÓN DE ARCHIVO}

Archivo Municipal de La Laguna, Fondo Antiguo, sección primera

- Caja F I: Fábricas Públicas.

- Caja F IX: Fortificaciones.

- Caja R VI: Reales Cédulas, Carpeta número 7.

- Papeles sueltos de Juan de Azoca, 1533-1560.

Archivo Histórico Provincial de Santa Cruz de Tenerife

- Protocolo Notarial de Francisco de Zambrana, 1565-1569 (PN 1.221). 